\title{
POLÍTICAS DE CONSTITUIÇÃO DO CONHECIMENTO ESCOLAR PARA O ENSINO MÉDIO NO RIO GRANDE DO SUL: UMA ANALÍTICA DE CURRÍCULO
}

Roberto Rafael Dias da Silva*

RESUMO: O presente estudo inscreve-se no campo dos Estudos Curriculares e examina as políticas contemporâneas de constituição do conhecimento escolar para o Ensino Médio no Estado do Rio Grande do Sul (Brasil). A partir de uma análise documental, foram estudados os principais documentos curriculares para o Ensino Médio produzidos pelo referido Estado, atribuindo ênfase à recente reforma nomeada como Ensino Médio Politécnico. O estudo justifica-se pelo lugar estratégico ocupado pelo Ensino Médio nas políticas contemporâneas de escolarização e pela relevância social e produtividade acadêmica de investigarmos as políticas de constituição do conhecimento escolar na contemporaneidade. Toma-se como objetivo geral o estabelecimento de um diagnóstico crítico das estratégias políticas que regulam a produção, a seleção e a distribuição do conhecimento escolar no Ensino Médio no referido contexto.

Palavras-chave: Políticas Curriculares; Conhecimento Escolar; Ensino Médio; Rio Grande do Sul.

POLITICAL CONSTITUTION OF SCHOOL KNOWLEDGE AT HIGH SCHOOL LEVEL IN RIO GRANDE DO SUL: AN ANALYTICS OF CURRICULA

ABSTRACT: This study falls within the field of Curriculum Studies and examines the contemporary political constitution of school knowledge at high school level in the state of Rio Grande do Sul (Brazil). From a documentary analysis, we studied the main curriculum documents for High School produced by that state, while emphasizing the recent reform named Polytechnic School. The study is justified by the strategic place of high school on contemporary politics of schooling and the social relevance and academic productivity of investigating the political constitution of school knowledge in Contemporaneity. It takes as a general objective the establishment of a critical diagnosis of the political strategies that regulate the production, selection and distribution of school knowledge in High School in the aforementioned context.

Keywords: Curriculum Policies; School Knowledge; High School; Rio Grande do Sul.

\footnotetext{
* Doutor em Educação pela Universidade do Vale do Rio dos Sinos (Unisinos); Professor do Programa de Pós-Graduação em Educação da Universidade Federal da Fronteira Sul (UFFS). E-mail: robertoddsilva@yahoo.com.br.
} 


\section{Introdução}

As últimas duas décadas assinalaram um intenso conjunto de reformas nas políticas de escolarização, em geral, e nas políticas de currículo, em particular (BALL, 2010; BALL; MAINARDES, 2011). Com a intenção de atender a educação básica, ressignificando-a para um mundo em permanentes mudanças, inúmeras dessas reformas tomaram o currículo como alvo privilegiado para o desencadeamento de novas possibilidades de organização da vida em sociedade (POPKEWITZ, 2009; VEIGANETO, 2008; LOPES; MACEDO, 2011). Desde a emergência de novas diretrizes curriculares, passando pela consolidação de modelos de avaliação de larga escala, as políticas de currículo estiveram na ordem do dia. Tal cenário não se circunscreveu apenas ao espaço brasileiro, uma vez que pesquisadores de diferentes países e diferentes perspectivas teóricas têm assinalado a produtividade acadêmica e política de considerarmos essas questões (MULLER, 2003; YOUNG, 2007; MOREIRA; CANDAU, 2008).

Sob a égide das condições políticas do capitalismo contemporâneo, podemos notar um amplo campo discursivo que se propõe a situar os currículos escolares no interior de novas gramáticas políticas e pedagógicas. Questões como a formação de capital humano, como a garantia de formação cidadã e a equidade social, assim como a competitividade do país, intensificaram-se nos argumentos públicos em defesa das reformas escolares (DALE; ROBERTSON, 2011; BALL, 2010). Em uma sociedade globalizada e delineada por uma economia movida a conhecimento, os currículos escolares estabeleceram-se a partir de outro perfil formativo, a saber: um sujeito inovador, pró-ativo e empreendedor (GRINBERG, 2007; GADELHA, 2009; SILVA, 2011).

Nas condições acima esboçadas, considerando o cenário de uma nomeada sociedade do conhecimento, nosso objetivo para o presente artigo passa por compreender os modos pelos quais o conhecimento escolar para o Ensino Médio tem sido produzido nas reformas curriculares do Estado do Rio Grande do Sul, Brasil, tomando como material empírico um conjunto de documentos publicados pelo referido sistema de ensino, que informam e orientam a reforma curricular nomeada como Ensino Médio Politécnico. Para tanto, entendemos que a pesquisa da qual este artigo deriva pode ser justificada a partir de duas questões, distintas e complementares. Trataremos de cada uma delas a seguir. 
A primeira questão a ser explicitada agrega-se ao interesse em examinar os intensos movimentos de reforma curricular no Ensino Médio brasileiro. Vale recordar que a partir do final dos anos de 1990, iniciam-se intensos movimentos internacionais de reformas e novas possibilidades organizativas para esse nível de ensino. Sob a influência de determinadas organizações multilaterais (LIBÂNEO, 2012), o país publicou a nova Lei de Diretrizes e Bases da Educação Nacional (Lei n 9.394/96), assim como um conjunto de novas normativas curriculares. Sob diferentes perspectivas, os estudos na área evidenciaram a possibilidade imediata de mudanças nessa etapa da Educação Básica, ora delineando seu significado nas novas dinâmicas econômicas dos anos de 1990, ora apontando a urgência em superar o caráter dualizante da formação dos estudantes ou, ainda, apontando o Ensino Médio como espaço de proteção social para as juventudes. Em geral, essas proposições colocam o currículo escolar e as práticas docentes, em suas políticas e práticas, como alvos privilegiados para mudanças (SOUZA, 2008; SILVA, 2012).

Ainda em consonância a essa justificativa, também se faz relevante destacar que investimentos em educação tecnocientífica no Ensino Médio têm-se constituído como um dos campos prioritários das atividades atuais da Unesco. O estímulo e as orientações a esse campo têm passado, em geral, por duas possibilidades de ação: ora contribuindo para o desenvolvimento econômico do país, ora desencadeando práticas que popularizam o acesso à ciência e à tecnologia como forma de despertar talentos. Em ambas as situações, podemos visibilizar o intenso e produtivo entrelaçamento entre as práticas educativas e o desenvolvimento econômico. Sob essa lógica, um determinado país opta por investimentos nessa área planejando resultados futuros ou, como afirma um importante documento daquele organismo internacional, realiza investimentos "à espera dos ovos de ouro" (UNESCO, 2005, p.4). Sob as condições do cenário descrito, ao longo do período estudado e articulado a essas condições políticas, o Estado do Rio Grande do Sul apresentou um conjunto diversificado de estratégias curriculares para o Ensino Médio, destacandose recentemente os programas Lições do Rio Grande (2009) e Ensino Médio Politécnico (2011).

Em decorrência de nossa trajetória investigativa, assim como da centralidade do Ensino Médio na agenda política nacional e internacional, nossa segunda questão mobilizadora do estudo articula-se com a deman- 
da de retomarmos o conhecimento escolar como objeto de estudo curricular (MOREIRA, 2005). Internacionalmente, autores como Young (2007; 2011), Müller (2003), Popkewitz (2009; 2010), Dussel (2009), Nóvoa (2009) e Charlot (2009), de perspectivas teóricas diferentes, têm apontado a necessidade de retomarmos investigações acerca da produção do conhecimento escolar, visto que, possivelmente, as atuais políticas de currículo "dizem muito pouco sobre o papel do próprio conhecimento na educação" (YOUNG, 2011, p.395). Segundo esses autores, o lugar ocupado pelo conhecimento escolar nas reformas contemporâneas de escolarização evidencia um amplo deslocamento das funções sociais da instituição escolar. Tal deslocamento estaria conduzindo a uma ressignificação das políticas de produção do conhecimento escolar (YOUNG, 2007).

Quanto ao cenário brasileiro dos estudos de currículo, também observamos resultados de pesquisa nessa direção. Estudos como os de Moreira (2005; 2010), Moreira e Candau (2008), Fabris (2008), Fabris e Traversini (2011) e Veiga-Neto (2008), dentre outros, têm assinalado a urgência em estudarmos os conhecimentos escolares sob as condições culturais contemporâneas. Nesse cenário de ressignificação dos currículos escolares, Fabris e Traversini (2011), ao estudarem escolas situadas em periferias do sul do Brasil, destacam que a escola tem assumido como sua principal ação a busca pela proteção e pela segurança social, fazendo com que os conhecimentos sejam secundarizados na formação dos sujeitos escolares daquele contexto. De forma mais provocativa e propositiva, Moreira (2005) tem defendido que, ainda que a criança e a sua cultura sejam indispensáveis para a vida escolar, é importante atribuir centralidade, no estudo e no planejamento das políticas de currículo, ao conhecimento escolar. "Insisto no sentido de que a eles se associe uma aguda preocupação com o conhecimento, com sua aquisição, com uma instrução ativa e efetiva, com um professor ativo e efetivo, que bem conheça, escolha, organize e ensine os conteúdos de sua disciplina ou área do conhecimento" (MOREIRA, 2005, p.37).

Metodologicamente, importa reiterar que desenvolvemos uma análise documental dos principais textos curriculares que orientam a constituição do Ensino Médio Politécnico. Selecionamos os referidos documentos através de suas possibilidades de intervenção no contexto escolar, dimensionando tanto aspectos prescritivos (como orientações, pareceres e propostas curriculares), quanto elementos de indução de determinadas práti- 
cas (como o tipo de planejamento ou de avaliação recomendados). Assim, precisamos indicar também que, ao operarmos com referenciais teóricos inspirados no pensamento de Michel Foucault, como exploraremos a seguir, no tratamento dos materiais empíricos, não ficamos circunscritos aos ditos e escritos em sua materialidade, mas exploramos as periferias de seus enunciados. Buscamos traçar um campo de visibilidades acerca dos regimes de governo que irrompiam dos textos analisados.

Assim sendo, buscamos considerar a produtividade acadêmica de investigarmos as políticas de constituição do conhecimento escolar na contemporaneidade. A questão que orientou o presente estudo sintetizase na seguinte formulação interrogativa: Que estratégias políticas regulam a produção, a seleção e a organização do conhecimento escolar no Ensino Médio no Estado do Rio Grande do Sul, no contexto de implementação do Ensino Médio Politécnico? Para problematizarmos essa questão, organizamos o presente artigo em três seções. Inicialmente, na primeira seção, inscreveremos o presente estudo no campo dos Estudos Curriculares, dimensionando-o através de uma das categorias principais desse campo o conhecimento escolar. $\mathrm{Na}$ segunda seção, esboçaremos uma descrição contextual das condições de possibilidade que permitem a emergência dos novos delineamentos para o Ensino Médio. Nesse sentido, priorizaremos as questões do pós-industrialismo, do capitalismo flexível e do neoliberalismo americano como aspectos vinculados aos novos sistemas de raciocínio pedagógico, emergentes em nosso tempo. Por fim, na terceira seção, realizaremos um estudo de uma das reformas da educação secundária implementada no Brasil ao longo da última década, o Ensino Médio Politécnico, desenvolvido no Estado do Rio Grande do Sul. Demarcaremos que, a partir das condições de possibilidade descritas na segunda seção, as políticas de constituição do conhecimento escolar produzidas nesse contexto vinculam-se a perspectivas de produção de "dispositivos de customização curricular", através da mobilização de outros sistemas de raciocínio pedagógico. Considerando as dimensões da otimização, da participação e da realização pessoal como características das sociedades pós-industriais, como definiu o sociólogo estadunidense Daniel Bell (1977), constatamos que, na política curricular examinada, os próprios estudantes são interpelados a produzir os seus percursos formativos, alicerçados nos seus interesses e nas oportunidades que a economia do conhecimento possa lhes oferecer. 


\section{Os Estudos Curriculares como grade de inteligibilidade}

O presente estudo inscreve-se no campo dos Estudos Curriculares, sobretudo nas suas vertentes contemporâneas que estudam as políticas de constituição do conhecimento escolar (YOUNG, 2007; 2011; MOREIRA, 2010). Para fins dessa contextualização teórica, importa destacar que os Estudos Curriculares, enquanto um campo teórico articulado às Ciências da Educação, caracterizam-se pelo seu hibridismo epistemológico (PACHECO; PEREIRA, 2007). Saberes de diferentes correntes teóricas, ou mesmo de distintos campos de saber, articulam-se na composição dessa área, ocasionando uma identidade conceitual bastante complexa e problemática (PACHECO, 2006; LOPES; MACEDO, 2011). Para além dessas questões, importa ressaltar, dentre outras indagações, a forte aproximação entre as políticas e as práticas de currículo com os processos de escolarização, visto que esteve, "desde a sua gênese, ligado a processos organizacionais com vista à elaboração de projetos de formação em contextos muito distintos, embora com ênfase para os que se prendem com a escolarização e com a formação de educadores e professores" (PACHECO, 2006, p.248).

Quando procuramos compreender as múltiplas possibilidades organizativas do currículo escolar, deparamo-nos com um conjunto de relações de poder e saber. Os currículos articulam-se com as políticas (macro e micro) que perfazem os cotidianos escolares, sendo regulados tanto pelas dimensões do Estado, quanto pelas tensões internas de seus atores e da comunidade na qual estão inseridos (POPKEWITZ, 2009; SILVA, 2007). Frente a essa condição é que a literatura contemporânea tem atribuído uma dimensão seletiva ao currículo, uma vez que ele "é sempre o resultado de uma seleção: de um universo mais amplo de conhecimentos e saberes seleciona-se aquela parte que vai constituir, precisamente, o currículo" (SILVA, 2007, p.15). Assim, o currículo pode ser lido como uma produção cultural.

Um tratamento analítico ao currículo e às políticas de escolarização que os sustentam passa fortemente pelo estudo de suas interfaces com os contextos mais amplos - sociais, políticos, econômicos. Sob esse olhar, é possível afirmar que o currículo apresenta-se como "um dispositivo em que se concentram as relações entre a sociedade e a escola, entre os saberes e as práticas socialmente construídos e os conhecimentos esco- 
lares" (MOREIRA; CANDAU, 2008, p.23). Articulada a essa abordagem, Pacheco sugere-nos que "a metodologia adequada ao currículo é a que consegue captar a legibilidade das situações de decisão nos mais distintos espaços organizacionais, sabendo-se que não se trata de um processo linear e técnico" (PACHECO, 2006, p.264).

Quando nos propomos a estabelecer algumas incursões investigativas no campo dos Estudos Curriculares, considerando suas múltiplas interconexões com as políticas de escolarização de nosso tempo, atribuímos especial interesse aos conhecimentos escolares. Pacheco, em um exercício de síntese, aponta que "o que mais define e caracteriza o percurso constitutivo do currículo é o conhecimento, alfa e ômega da escola" (PACHECO, 2006, p.256). Interessa-nos refletir acerca dos diferentes tensionamentos no campo dos conhecimentos escolares que permitem, sobretudo na Educação Básica, a emergência de um conjunto de novas pautas políticas para a escolarização obrigatória. Ainda que os textos curriculares contemporâneos se encaminhem para a formação de sujeitos autônomos, críticos e criativos, nossa intenção passa por colocar sob suspeita muitas dessas dimensões. Examiná-las criticamente implica a elaboração de outros movimentos de análise que privilegiem a centralidade do conhecimento escolar. "O conhecimento, nas dinâmicas sociais, culturais e ideológicas que o definem, constitui a lógica da elaboração, gestão e avaliação do currículo pelo que as aprendizagens dos alunos não são meros processos técnicos mediados por indicadores de desempenho" (PACHECO, 2006, p.264).

Articularemos a realização de um estudo acerca das políticas de constituição do conhecimento escolar aos estudos sobre a governamentalidade, produzidos sob inspiração do pensamento de Michel Foucault ${ }^{1}$ (FOUCAULT, 2008a; FOUCAULT, 2008b). Tal articulação tem-se mostrado fértil em diferentes estudos na área; tanto internacionalmente (Ó, 2003; NARODOWSKI, 1999; BALL，2010; POPKEWITZ，2009; FIMYAR, 2009; SIMONS; MASSCHELEIN, 2006), quanto no cenário brasileiro (VEIGA-NETO, 2008; LOPES, 2009; SILVA; FABRIS, 2012; SILVA; FABRIS, 2010).

O uso da governamentalidade de que procuramos lançar mão aproxima-se daquilo que Noguera (2009) aponta como "noção metodológica". Conforme o pesquisador colombiano, "uma noção metodológica é uma ferramenta para pensar, um instrumento para operar sobre um pro- 
blema" (NOGUERA, 2009, p.23). Dessa forma, a noção de governamentalidade é uma ferramenta desenvolvida por Foucault que serviu para "O desenvolvimento de sua atividade de investigação e ensino" (NOGUERA, 2009, p.23). Nessa direção, tal como sugeriu Foucault, o governo é posicionado como um campo de intervenção que opera na "condução das condutas" dos indivíduos ou, ainda, no modo como somos conduzidos e nos conduzimos. Em uma importante sistematização na área, Dean (1999) posiciona o governo como "realização efetuada no plural". Governar, então, implicaria conduzir a conduta dos diferentes indivíduos. A partir dessa abordagem, a noção de governo é ampliada, não permanecendo exclusivamente nas diferentes modalidades de autoridade exercidas sobre os outros, mas incluindo também a nós mesmos. Ao analisarmos tais formas de condução, tomamos como objeto "aquelas que tentam moldar, esculpir, mobilizar e lidar com escolhas, desejos, aspirações, necessidades, vontades e estilos de vida de indivíduos e grupos" (DEAN, 1999, p.12).

Essa abordagem não posiciona as práticas de governo sob arranjos de modelos idealizados de poder, nem mesmo as posiciona como efeitos ou produtos de contradições ou hegemonias. Uma analítica de governo "examina as condições nas quais se formam, são mantidos e transformados os regimes de práticas" (DEAN, 1999, p.21). Assim sendo, ao interrogarmos pelas políticas contemporâneas de constituição do conhecimento escolar no Ensino Médio, servindo-nos da noção foucaultiana de governamentalidade, nosso interesse investigativo alicerça-se na possibilidade de descrever as múltiplas estratégias políticas que regulam a produção, a seleção e a organização do conhecimento escolar no Ensino Médio, no Estado do Rio Grande do Sul, no referido período.

Dessa perspectiva teórica, sugere-se que tal regulação pode operar tanto nos Estados e demais agentes públicos, quanto no sujeito em relação a si mesmo. Em decorrência desse pressuposto, interessa estabelecer um mapeamento dos sistemas de raciocínio pedagógico (POPKEWITZ, 2009), visibilizados nos referidos documentos, que operam na seleção dos conhecimentos escolares a serem estudados nas escolas de Ensino Médio. Compreender os referidos sistemas implica o reconhecimento de que os conhecimentos escolares são construções sociais, produzidas nas condições históricas, econômicas e políticas de seu tempo. Parafraseando Dean (1999), anteriormente referido, buscaremos produzir 
uma analítica de currículo. Tal analítica possibilitará um exame das condições contemporâneas de produção do conhecimento escolar, um olhar pelos seus modos de constituição.

Para a realização de tal empreendimento, o uso da governamentalidade como ferramenta analítica permite uma leitura crítica das diferentes racionalidades políticas contemporâneas. De acordo com Foucault (2008b), exercer essa crítica "consiste em determinar em que condições e com quais efeitos se exerce uma veridição, isto é, mais uma vez, um tipo de formulação do âmbito de certas regras de verificação e de falsificação" (FOUCAULT, 2008b, p.50). Em outras palavras, faz-se necessário estabelecer um diagnóstico das condições políticas que tornam determinado objeto possível em uma dada sociedade e, ao mesmo tempo, possibilita "um tipo de estudo preocupado com uma análise das condições específicas para determinadas entidades emergirem, existirem e mudarem" (DEAN, 1999, p.20). A seguir, iniciaremos a descrição de algumas das condições sociais e econômicas de nosso tempo.

\section{Pós-industrialismo, capitalismo flexível e neoliberalismo: dimensões contextuais}

Transcorrem mais de três décadas da elaboração do diagnóstico produzido pelo sociólogo estadunidense Daniel Bell acerca do advento da sociedade pós-industrial (1977). Para explicitar adequadamente as mudanças sociais que estavam em curso, o sociólogo servia-se de três categorias básicas: estrutura social, política e cultura. Por estrutura social, o autor referia-se ao conjunto temático que envolve o sistema econômico, as tecnologias e as ocupações. Quanto à política, postulava que esta se posiciona nas dinâmicas de distribuição da moderna sociedade e na resolução de diferentes conflitos e exigências individuais ou coletivas. Acerca da questão cultural, Bell dimensiona as diferentes formas de produção simbólica.

Com o início da década de 1970, Bell começava a observar um conjunto de deslocamentos analíticos em cada uma de suas três categorias privilegiadas. Em sua leitura, a otimização, a participação e a realização pessoal adquiriam maior relevância na produção da vida social a partir daquele contexto. 
Na moderna sociedade ocidental, o princípio axial da estrutura social é economizar - uma maneira de atribuir recursos de acordo com os princípios da redução de custos, capacidade de substituição, otimização, maximização, etc. O princípio axial da política moderna é a participação, por vezes mobilizado ou controlado, por vezes exigido de baixo para cima. O princípio axial da cultura é o desejo de valorização e de aprimoramento do eu (BELL, 1977, p.26).

O diagnóstico preliminar elaborado por Bell (1977), por ele nomeado como uma "tentativa de previsão social", em muitos aspectos, antecipa os desenvolvimentos posteriores das ciências sociais. Ao situar, por exemplo, o economizar como um princípio valorativo, o sociólogo põe em evidência elementos indispensáveis para a percepção dos pressupostos neoliberais nas políticas contemporâneas. Da mesma forma, ao encaminhar a centralidade da participação política, antecipa inúmeros movimentos de reivindicação ao Estado e de suas estratégias de ação pelos diferentes segmentos da sociedade civil. E, ainda, acerta os delineamentos de uma cultura individualista, marcada pelas tensões de um indivíduo em autoformação permanente.

Ao articular esse diagnóstico, Bell traça os principais pressupostos que orientarão a emergente sociedade pós-industrial. Seu trabalho torna-se mais explícito na medida em que define algumas dimensões importantes desse conceito - sociedade pós-industrial. A transição para uma economia de serviços, a predominância de grupos profissionais com grande domínio técnico, o conhecimento como vetor de inovação, o uso ostensivo das ferramentas tecnológicas e os novos processos de tomada de decisão são alguns dos aspectos descritos pelo sociólogo. Entretanto, dentre inúmeras definições esboçadas, duas significações interessam aos objetivos deste texto.

Finalmente, a significação da sociedade pós-industrial é a seguinte:

1. Ela reforça o papel da ciência e dos valores cognitivos, como necessidade institucional básica da sociedade;

2. Ao tomar decisões de maneira mais técnica, ela traz o cientista ou o economista mais diretamente para dentro do processo político [...] (BELL, 1977, p.60).

$\mathrm{Na}$ composição analítica proposta pelo sociólogo, as dimensões da ciência, do conhecimento e das decisões técnicas estarão articuladas, visto que a sociedade passa a ser regida por outros processos de tomada 
de decisão. Em sua abordagem, a lucratividade e a produtividade tornamse os índices de avaliação do sucesso de uma sociedade. "Elas constituem a prova de que estão sendo atendidas as exigências do mercado e as da distribuição eficiente dos recursos no interior da firma e entre os membros da sociedade" (BELL, 1977, p.313). Em outras palavras, a ênfase valorativa na ciência e na técnica em uma sociedade pós-industrial decorre de seus potenciais de lucratividade e produtividade. A leitura sociológica produzida por Daniel Bell, no início da década de 1970, nos conduz a uma observação atenta das modificações no mundo do trabalho e das políticas de formação humana, sobretudo pela emergência dos princípios neoliberais, conforme desenvolveremos posteriormente.

Em estudo contemporâneo, Sennett (2001) propõe-se a examinar as condições culturais do contexto que denomina como "capitalismo flexível", sobretudo em suas consequências na constituição das subjetividades dos trabalhadores. O sociólogo assinala, em sua abordagem, que a flexibilidade, típica das condições capitalistas de nosso tempo, apresentase como um conceito central não apenas ao campo econômico, mas produz delineamentos significativos ao campo do trabalho, uma vez que se pede "aos trabalhadores que sejam ágeis, estejam abertos a mudanças a curto prazo, assumam riscos continuamente, dependam cada vez menos de leis e procedimentos formais" (SENNETT, 2001, p.9). Nessa abordagem, a flexibilidade pode ser lida como um aspecto determinante para os modos de vida contemporâneos.

As modificações produzidas no mundo do trabalho conduziram os sujeitos a modos diferentes de experienciarem suas relações com a carreira, com a estabilidade e com o planejamento a longo prazo. Sob as condições do capitalismo flexível, a própria ideia de uma carreira, em sua acepção tradicional, é deslocada para uma dinâmica de incertezas permanentes, nas quais os trabalhadores são interpelados a estágios contínuos de qualificação. ${ }^{2}$ Tal perspectiva materializa-se na questão de que o desejo de mudança passa a ser requerido como uma disposição fundamental para os candidatos ao mercado de trabalho. Sennett descreve que a lógica do “"não há longo prazo' significa mudar, não se comprometer, não se sacrificar” (SENNETT, 2001, p.25).

Conviver com as rápidas mudanças sociais de nosso tempo implica a aceitação da flexibilidade como um modo de vida. Os sistemas de poder que se derivam do primado da flexibilidade desdobram- 
se em três elementos: "reinvenção contínua de instituições; especialização flexível de produção; e concentração de poder sem centralização" (SENNETT, 2001, p.64). As organizações derivadas desse cenário flexibilizam seus tempos e seus espaços, na medida em que não centralizam estratégias, nem concentram o poder. A experiência do tempo, ou "flexitempo", como sugere o sociólogo, pode ser apresentada como "um mosaico de pessoas trabalhando em horários diferentes, mas individualizados" (SENNETT, 2001, p.66).

Considerando o conjunto argumentativo produzido por Daniel Bell e Richard Sennett, temporalmente distanciados por mais de duas décadas, faz-se possível descrever as inter-relações dessas abordagens no cenário conhecido como neoliberalismo americano, sobretudo nas formulações clássicas de Milton Friedman. Em seu livro Capitalismo e liberdade (1977), o economista descreve as bases teóricas do neoliberalismo: tanto diferenciando esse pensamento econômico dos modelos keynesianos predominantes na época, quanto atribuindo visibilidade à promoção do capitalismo competitivo e das relações entre liberdade e individualismo. Vale referir que compreender a emergência do neoliberalismo, sob essa perspectiva, implica seu reconhecimento como um modo de vida, para além de apenas um sistema econômico (FOUCAULT, 2008b).

Ao apresentar as doutrinas econômicas que serão exploradas ao longo de seu livro, Friedman propõe-se a estabelecer comparações entre um governo planejado e um sistema de liberdade econômica. Segundo o autor, um governo pode ser capaz de melhorar as condições de vida de sua população através de padrões de nutrição ou habitação, dentre outros; entretanto, em sua abordagem, "o governo não poderá jamais imitar a variedade e a diversidade da ação humana" (FRIEDMAN, 1977, p.13). O ponto crítico das práticas de governo é que suas práticas de planejamento, em geral, ao longo do processo, substituem o progresso pela estagnação, ou, ainda, trocam a variedade pela uniformidade.

Considerando essa crítica das práticas de governo, o economista da Escola de Chicago demarcará que o compromisso de sua abordagem conceitual está na compreensão do capitalismo competitivo, em outras palavras, na "organização da maior parte da atividade econômica através da empresa privada operando num mercado livre" (FRIEDMAN, 1977, p.13). Ao mesmo tempo, sua questão de fundo busca desenvolver a hipótese de que a liberdade econômica é condição para a liberdade política, 
sobretudo através da concepção de uma sociedade que se dedique ao tema da liberdade. Para levar adiante essa intenção, Friedman sugere uma retomada dos principais pressupostos do liberalismo clássico, redimensionando-os às condições do seu tempo. Assim sendo, torna-se um dos grandes arautos da defesa da redução do papel do Estado ("em assuntos econômicos"), do mercado livre como estratégia de produção de um mundo pacífico e da ampliação do papel dos indivíduos e dos agentes privados.

O modo pelo qual esse sistema competitivo é mobilizado dá-se através da liberdade individual. As diferentes questões sociais, derivadas de uma vida coletiva, deveriam ser resolvidas pelos próprios indivíduos. Em outras palavras, na acepção neoliberal, "o objetivo mais importante dos liberais é deixar os problemas éticos a cargo do próprio indivíduo" (FRIEDMAN, 1977, p.21). O exemplo proposto pelo economista é a escolha da cor de uma gravata, na qual os indivíduos poderiam optar pela que desejassem, sem se submeterem aos desejos da maioria.

Uma ressalva ainda é feita: a ênfase no livre mercado não corresponde à eliminação das práticas de governo. Porém, a posição do governo é deslocada da função do provimento: "um governo é essencial para a determinação das 'regras do jogo', é um árbitro para interpretar e pôr em vigor as regras estabelecidas” (FRIEDMAN, 1977, p.23). O papel destinado ao governo, então, está em buscar meios para resolver aquilo que o mercado não consegue atender, seja arbitrando as regras de competição, seja provendo as condições àqueles que não podem concorrer com liberdade. ${ }^{3}$

Assim, pode-se observar que as práticas de governo também operam na perspectiva de ampliar o potencial de competitividade daqueles que estariam segregados desse processo. Crianças, pessoas com deficiência, jovens ou pobres devem receber investimentos que ampliem suas oportunidades. Tais investimentos serão conhecidos como capital bumano, visto que objetivam ampliar a potencialidade econômica dos indivíduos. "Se ele se tornar produtivo, será recompensado, numa sociedade de livre empresa, recebendo pagamento por seus serviços - mais alto do que receberia em outras circunstâncias" (FRIEDMAN, 1977, p.90).

Estabelecendo uma leitura ampliada desse cenário, é possível inferir que o papel do governo, em uma sociedade neoliberal, está em produzir agenciamentos que ampliem as oportunidades dos sujeitos, ao mesmo tempo em que devem regulamentar o processo competitivo. 
Ainda que o governo ocupe esse lugar privilegiado, sob essa lógica, "os indivíduos [é que] devem ser responsabilizados pelo custo de seu investimento e receber as recompensas" (FRIEDMAN, 1977, p.94). Dessa forma, podemos compreender, dentre outras questões, os modos pelos quais as reformas curriculares têm privilegiado uma lógica de equidade concomitantemente à promoção de currículos que tenha os indivíduos e suas escolhas como centro propulsor da vida escolar. Considerando as dimensões contextuais acima delineadas, a seguir, apresentaremos nossas primeiras impressões empíricas produzidas em nossa investigação.

\section{Ensino Médio Politécnico: impressões empíricas}

Ao longo da última década, o Estado do Rio Grande do Sul apresentou alguns indicadores desfavoráveis em seus processos de escolarização no Ensino Médio, última etapa da Educação Básica. Considerando esses dados, da mesma forma que as demandas emergentes das políticas curriculares para o Ensino Médio a nível nacional e internacional, ${ }^{4} \mathrm{o}$ Estado do Rio Grande do Sul propôs uma reforma curricular para essa etapa da Educação Básica, intitulada como Ensino Médio Politécnico. Do ponto de vista curricular, a Proposta Pedagógica orientadora da reforma justifica sua necessidade devido ao fato de que, no referido contexto, "O ensino se realiza mediante um currículo fragmentado, dissociado da realidade sócio-histórica, e, portanto, do tempo social, cultural, econômico e dos avanços tecnológicos da informação e da comunicação" (RIO GRANDE DO SUL, 2011, p.4). Quanto aos cursos integrados com a educação profissional, a referida proposta justifica que os atuais formatos de cursos em vigência não refletiam a realidade regional, não dialogavam com as novas tecnologias e estavam dissociados do desenvolvimento econômico do Estado.

O documento orientador da Proposta Pedagógica fundamentase, inicialmente, na premissa normativa de que o Ensino Médio constituise como a etapa final da Educação Básica. Retoma a Lei de Diretrizes e Bases da Educação Nacional (Lei n. 9.394/1996), em seu art. 22, ao assinalar que a Educação Básica tem por finalidade a formação para o exercício da cidadania, para progredir no trabalho e em estudos posteriores. 
Posiciona-se também em aproximação às novas diretrizes curriculares brasileiras, bem como aos novos programas do Ministério da Educação, apontando a articulação das áreas do conhecimento com as dimensões da ciência, da tecnologia, da cultura e do trabalho. Assim sendo, defende que os novos currículos escolares a serem implementados não devem postular uma abordagem profissionalizante, uma vez que o trabalho é posicionado como um princípio educativo. Antes de avançarmos nessa composição analítica, precisamos destacar que nossa intenção não estará em produzir uma apropriação das categorias marxianas vinculadas à politecnia, mas descrevê-las em seus diferentes usos mobilizados nos documentos estudados.

Ancorado nas concepções acima esboçadas, o Ensino Médio Politécnico é definido a partir de novas relações entre teoria e prática, bem como na composição dos conhecimentos escolares, conforme apresentaremos a seguir.

Ensino Médio Politécnico: Tem em sua concepção a base na dimensão politécnica, constituindo-se no aprofundamento da articulação das áreas de conhecimentos e suas tecnologias, com os eixos Cultura, Ciência, Tecnologia e Trabalho, na perspectiva de que a apropriação e a construção de conhecimento embasam e promovem a inserção social da cidadania (RIO GRANDE DO SUL, 2011, p.10).

A proposta considera a importância de produzir a formação escolar a partir de um novo princípio educativo, vinculado às mudanças ocorridas no mundo do trabalho, bem como às novas condições da educação contemporânea. O trabalho é posicionado como um princípio educativo; entretanto, é situado junto ao advento da microeletrônica, permitindo com que "tanto o trabalho quanto a vida social se modifiquem, passam a ser regidos pela dinamicidade e pela instabilidade a partir da produção da ciência e da tecnologia" (RIO GRANDE DO SUL, 2011, p.13). Diferentemente dos modelos fordistas de organização do trabalho, com os delineamentos atuais, passam a adquirir centralidade os processos de "intelectualização das competências, que demanda raciocínio lógico formal, domínio das formas de comunicação, flexibilidade para mudar, capacidade de aprender permanentemente e resistência ao estresse" (RIO GRANDE DO SUL, 2011, p.13). Diante desse cenário, a proposta pedagógica defende a emergência de um novo princípio educativo, marcado pelo trabalho intelectual. 
Em atendimento ao novo princípio, a proposta curricular do Rio Grande do Sul para o Ensino Médio opta por revitalizar o conceito de politecnia, demarcando suas possibilidades de compreensão como um "domínio intelectual da técnica". A politecnia é apresentada como princípio organizador dos currículos escolares para essa etapa da Educação Básica. ${ }^{5}$ Mesmo que o nomeado Ensino Médio Politécnico não objetive a profissionalização, posiciona-se na articulação das demandas sociais e das questões advindas do mundo do trabalho, promovendo práticas formativas tecnocientíficas e visando à transformação da realidade social.

Do ponto de vista da organização curricular, a politecnia supõe novas formas
de seleção e organização dos conteúdos a partir da prática social, contemplan-
do o diálogo entre as áreas do conhecimento; supõe a primazia da qualidade
da relação com o conhecimento pelo protagonismo do aluno sobre a quanti-
dade de conteúdos apropriados de forma mecânica; supõe a primazia do sig-
nificado social do conhecimento sobre os critérios formais inerentes à lógica
disciplinar. A construção desse currículo integrado supõe a queda de paradig-
mas e só poderá ocorrer pelo trabalho coletivo que integre os diferentes ato-
res que atuam nas escolas, nas instituições responsáveis pela formação de pro-
fessores e nos órgãos públicos responsáveis pela gestão (RIO GRANDE DO
SUL, 2011, p.15).

$\mathrm{Na}$ leitura produzida pela política curricular para o Ensino Médio no Rio Grande do Sul, a politecnia implica movimentos de integração curricular. Tais movimentos são esboçados tanto nas relações entre os conhecimentos de formação geral e os profissionais, quanto nas relações entre as áreas do conhecimento. Em torno do conhecimento, a proposta orientadora da reforma revisa alguns documentos publicados pela rede municipal de Porto Alegre, na segunda metade dos anos de 1990, compreendendo o conhecimento como "um processo humano, histórico, incessante, de busca de compreensão, de organização, de transformação do mundo vivido e sempre provisório" (RIO GRANDE DO SUL, 2011, p.16). Acompanhando essa concepção, o documento posiciona o currículo como "o conjunto das relações desafiadoras das capacidades de todos". Em outras palavras, a referida proposta entende o conhecimento enquanto uma construção, e o currículo escolar como uma disposição de experiências formativas que desafiem as capacidades de todos os sujeitos.

Para a operacionalização dessa proposta, um conjunto de reformas foi delineado para o Ensino Médio Politécnico. Em sintonia com a ten- 
dência já visibilizada no Programa Ensino Médio Inovador (PROEMI), do Ministério da Educação, a proposta do Sul do Brasil também determina a ampliação dos tempos escolares, fazendo com que essa etapa da Educação Básica aumente 200 horas-aula por ano letivo. O referido acréscimo, conforme explicitamos na Tabela 1, permitirá com que a carga horária total do Ensino Médio chegue a 3.000 horas. Ainda no que tange à ampliação da carga horária, a proposta curricular propõe que esse acréscimo "se traduzirá por possibilidades de estágios ou aproveitamento de situações de emprego formal ou informal, desde que seu conteúdo passe a compor os projetos desenvolvidos nos seminários integrados e, com isso, venha a fazer parte do currículo do curso" (RIO GRANDE DO SUL, 2011, p.25).

\section{TABELA 1}

Distribuição anual da carga horária do Ensino Médio

\begin{tabular}{c|c|c|c|c} 
Blocos curriculares & $\mathbf{1}^{\mathbf{0}}$ ano & $\mathbf{2}^{\mathbf{0}}$ ano & $\mathbf{3}^{\mathbf{0}}$ ano & Total \\
\hline Formação geral & $750 \mathrm{~h}$ & $500 \mathrm{~h}$ & $250 \mathrm{~h}$ & $1.500 \mathrm{~h}$ \\
Parte diversificada & $250 \mathrm{~h}$ & $500 \mathrm{~h}$ & $750 \mathrm{~h}$ & $1.500 \mathrm{~h}$ \\
Total & $1.000 \mathrm{~h}$ & $1.000 \mathrm{~h}$ & $1.000 \mathrm{~h}$ & $3.000 \mathrm{~h}$
\end{tabular}

Fonte: Rio Grande do Sul (2011).

De acordo com a legislação educacional de nosso país, a proposta é organizada em dois grandes blocos: formação geral e parte diversificada. Segundo as definições explicitadas, a divisão entre os blocos não é produzida de forma rígida ou estática, visto que sua intenção é produzir práticas pedagógicas contextualizadas e interdisciplinares. Sob nossa interpretação, porém, as concepções de cada um dos blocos evidenciam aspectos relevantes.

Entende-se por formação geral (núcleo comum) um trabalho interdisciplinar com as áreas do conhecimento, com o objetivo de articular o conhecimento universal sistematizado e contextualizado com as novas tecnologias, com vistas à apropriação e integração com o mundo do trabalho. Entende-se por parte diversificada (humana-tecnológica-politécnica) a articulação das áreas do conhecimento, a partir de experiências e vivências, com o mundo do trabalho, a qual apresente opções e possibilidades para posterior formação profissional nos diversos setores da economia e do mundo do trabalho (RIO GRANDE DO SUL, 2011, p.25). 
De imediato, é possível observar a ênfase atribuída às experiências (individuais e sociais) dos estudantes e aos modos pelos quais a articulação entre os diferentes conhecimentos será produzida por uma aproximação ao mundo do trabalho. Essa articulação é materializada no Ensino Médio Politécnico através da efetivação de projetos elaborados em Seminários Integrados, organizados pelos professores e alunos "desde o primeiro ano e em complexidade crescente" (RIO GRANDE DO SUL, 2011, p.26). Os seminários integrarão a carga horária da parte diversificada, aumentando gradativamente sua carga horária ao longo do curso. A referida relevância é justificada na sua função de organizar "o planejamento, a execução e a avaliação de todo o projeto político-pedagógico, de forma coletiva, incentivando a cooperação, a solidariedade e o protagonismo do jovem adulto" (RIO GRANDE DO SUL, 2011, p.26).

Os Seminários Integrados serão implementados através do desenvolvimento de projetos. Conforme o documento examinado, tais projetos podem ser traduzidos "por práticas, visitas, estágios e vivências [que] poderão também ocorrer fora do espaço escolar e fora do turno que o aluno frequenta' (RIO GRANDE DO SUL, 2011, p.26). Acerca desse aspecto, destaca-se a pesquisa como dimensão metodológica que organiza e estrutura os seminários; entretanto, a prática da pesquisa deverá ser mobilizada a partir de necessidades ou situações-problema, delimitadas em uma lista prévia de "eixos temáticos transversais" (Tabela 2).

\section{TABELA 2}

Temas prioritários para a composição da parte diversificada no Ensino Médio

Eixos temáticos transversais para a parte diversificada

1. Acompanhamento Pedagógico
2. Meio ambiente
3. Esporte e Lazer
4. Direitos Humanos
5. Cultura e Artes
6. Cultura digital
7. Prevenção e Promoção da Saúde
8. Comunicação e uso de mídias
9. Investigação no campo das Ciências da Natureza
10. Educação Econômica e áreas de produção

Fonte: Rio Grande do Sul (2011). 
Ainda no que se refere aos Seminários Integrados, importa destacar sua gradativa ampliação da carga horária ao longo dos três anos do Ensino Médio. De acordo com a matriz curricular do Ensino Médio Politécnico (Tabela 3), apresentada como anexo da proposta examinada, é possível notar um crescimento significativo do espaço destinado aos seminários.

\section{TABELA 3}

Matriz curricular do Ensino Médio Politécnico

\begin{tabular}{c|c|c|c}
$\begin{array}{c}\text { Blocos e disciplinas } \\
\text { Formação Geral }\end{array}$ & $\begin{array}{c}\mathbf{1}^{\mathbf{0}} \text { ano } \\
\mathbf{C H / S e m}\end{array}$ & $\begin{array}{c}\mathbf{2}^{\mathbf{0}} \text { ano } \\
\mathbf{C H} / \text { Sem }\end{array}$ & $\begin{array}{c}\mathbf{3}^{\mathbf{0}} \text { ano } \\
\mathbf{C H} / \text { Sem }\end{array}$ \\
\hline $\begin{array}{c}\text { Linguagens e suas tecnologias } \\
\text { Matemática }\end{array}$ & 8 & 6 & 5 \\
$\begin{array}{c}\text { Ciências da natureza e suas tecnologias } \\
\text { Ciências humanas e suas tecnologias }\end{array}$ & 4 & 2 & 1 \\
Parte diversificada & 6 & 6 & 3 \\
Língua Estrangeira/ Ensino Religioso & 4 & 4 & 4 \\
Seminários Integrados & 2 & 5 & 6 \\
TOTAL & 30 & 7 & 11 \\
$\quad$ & 30 & 30
\end{tabular}

Fonte: Rio Grande do Sul (2011).

Ao examinarmos a Tabela 3, podemos constatar que determinadas áreas do conhecimento, como a Matemática, por exemplo, são reduzidas em sua carga horária e no seu lugar epistemológico ocupado no currículo escolar. Em outras palavras, não se faz difícil de deduzir que há uma tendência em atribuir centralidade às experiências sociais dos estudantes, seus interesses e modos de vida e trabalho. A inserção no mercado de trabalho articulada aos interesses individuais dos estudantes delineiam espaços de aprendizagem marcados por percursos formativos regidos por lógicas individuais. A carga horária dos Seminários Integrados, no terceiro ano, atinge 11 períodos semanais. A politecnia, esboçada nessa proposta, distancia-se do tradicional conceito das teorizações neomarxistas em educação, na medida em que toma como enfoque central as experiências e os interesses dos jovens. ${ }^{6}$ Notamos uma tendência a produzir outros modos de interação juvenil com suas trajetórias de escolarização, alicerçadas nos padrões da otimização, da participação e da realização pessoal, tal como os axiomas da sociedade pós-industrial descritos por Bell (1977) e citados na seção anterior. Ampliando uma tendência das políticas curriculares brasileiras para o Ensino Médio, a saber: a multiplicidade de percur- 
sos formativos (BRASIL, 2012), no Ensino Médio Politécnico, vemos emergir uma concepção de currículo (e de conhecimento escolar) com formas mais flexíveis, que designaremos, a partir deste momento, como "dispositivos de customização curricular". A escolha dessa noção não implica uma negação dos saberes culturais dos estudantes, mas uma compreensão do processo de individualização de seus interesses e experiências formativas.

\section{Customização curricular no Ensino Médio: outros sistemas de raciocínio pedagógico}

Partindo da perspectiva curricular de multiplicação dos percursos formativos, derivada das recentes diretrizes curriculares para essa etapa da Educação Básica, ${ }^{7}$ o Ensino Médio Politécnico possibilita que, na somatória dos três anos letivos, metade da carga horária dos estudantes seja ocupada pela parte diversificada e que, para os estudantes do terceiro ano, 36,6\% da carga horária seja destinada aos Seminários Integrados. Tais seminários, conforme foram apresentados na seção anterior, são produzidos a partir dos interesses e escolhas individuais dos estudantes, podendo ser traduzidos em estágios, vivências, visitas e experiências diversas. Para materializar conceitualmente esse processo em curso no Estado do Rio Grande do Sul, mas também evidenciado em outros contextos internacionais, ${ }^{8}$ utilizamos a noção de "dispositivos de customização curricular". Valemo-nos dessa forma de nomear devido às fortes articulações da proposta examinada aos princípios fabricados pelas sociedades pós-industriais e neoliberais, conforme destacamos desde a segunda seção desta analítica.

O uso da expressão "customização" tem-se multiplicado nas diferentes práticas sociais contemporâneas. Diferentes práticas culturais de nosso tempo apontam para a customização de roupas, sites, blogs, automóveis, maquiagens, cortes de cabelo, dentre outros aspectos. Customizar tornou-se um imperativo para quem busca individualizar sua forma de estar no mundo. Importa destacar que a palavra customização é uma criação do campo da moda nos Estados Unidos, desde a década de 1990, sendo derivada da expressão "custom made". O fazer do seu jeito, ou sob medida, já estava presente no Brasil no final da referida década, sendo considerado como um sinônimo para as formas de vida que buscam dife- 
renciar-se das outras pessoas, fazem com que os sujeitos conduzam-se com criatividade. Ao verificarmos diferentes sites de moda, por exemplo, notamos a pulverização discursiva desse conceito e, sobretudo, sua consolidação nas publicações dirigidas ao público juvenil..$^{9}$ Nessa gramática, "fazer do seu jeito" significa personalizar seus objetos e suas características de modo que se produza com originalidade e individualidade. Customizar também pode ser entendido como produzir novos sentidos para um objeto que está em desuso ou de que a pessoa não goste mais.

Nessa direção, sob as condições até aqui descritas, posicionamos os modos de operação da política curricular examinada enquanto um dispositivo de customização curricular. Em outras palavras, tal política favorece uma intensa flexibilização dos processos formativos, permitindo que os estudantes possam escolher livremente os aspectos concernentes à sua formação escolar. O critério epistemológico que perfaz a argumentação que sustenta a referida proposta é posicionado na indissociabilidade entre as "dimensões sócio-históricas e os processos culturais" (RIO GRANDE DO SUL, 2011, p.15), ao mesmo tempo em que visa ajustar-se "à dinamicidade da produção em ciência e tecnologia que caracterizam os processos sociais e produtivos contemporâneos" (p.12). Através de uma complexa hibridização ideológica, a referida proposta coloca em movimento uma ideia que visa a conciliar as práticas culturais e o desenvolvimento capitalista, tomando o interesse dos estudantes como um centro. ${ }^{10}$

Para os pesquisadores da história das políticas de escolarização no Brasil, tais pressupostos colocados em ação não se traduzem em novidades. A própria noção de uma "escola sob medida" é produto das importantes teorizações pedagógicas de Edouard Claparède (1973), escritas nas primeiras décadas do século XX. Claparède produziu estudos pedagógicos que atribuíam centralidade ao interesse dos sujeitos escolares, delineou uma concepção educacional alicerçada nos conceitos de escolhas individuais e diversidade de aptidões, chegando a afirmar que "o indivíduo é tudo" (CLAPARÈDE, 1973, p.187). Ao reconhecer que era impossível ter uma escola para cada aluno, o psicólogo francês defendia uma "escola adaptada à mentalidade de cada um, uma escola que se acomode tão perfeitamente aos espíritos, quanto uma roupa ou um calçado sob medida o fazem para o corpo ou para o pé" (CLAPARÈDE, 1973, p.187). A escola claparediana, por ele nomeada como o "regime do futuro", sus- 
tentava-se em um regime de opções, no qual se permitia que os estudantes fossem agrupados de acordo com suas aptidões intelectuais.

A metade, mais ou menos, destas horas de aula seriam comuns a todos os alunos. Seriam reservadas ao ensino de programa mínimo, dos elementos ou dos fundamentos de cada disciplina. Quanto às outras dez horas obrigatórias para cada aluno, poderiam escolhê-las e combiná-las a seu gosto entre as que figuram no horário geral (como se faz nas Universidades). Essas aulas, livremente escolhidas, seriam complementos dos cursos gerais, ou estudos especiais, ou ainda lições de exercícios, nas quais se aprofundariam certos ensinamentos (CLAPARÈDE, 1973, p.189).

Claparède defendia ainda que seu regime de opções não eliminaria a preocupação com uma cultura geral, visto que os programas comuns garantiriam isso. Concomitantemente, o psicólogo ainda sustenta que seu modelo de escola contribui para uma nova cultura intelectual, visto que "cada uma dessas disciplinas é como um meio próprio para o desencadeamento dos processos intelectuais" (CLAPARÈDE, 1973, p.191). O modelo pedagógico da escola claparediana valia-se das diferentes disciplinas escolares no planejamento dos processos formativos; entretanto, deslocava a ênfase para os próprios indivíduos. Em suas palavras, "não esqueçamos que, trabalhando para o indivíduo, desenvolvendo sua capacidade, sua originalidade, valorizando suas forças e sua riqueza latentes, trabalhamos também, e sobretudo, pela sociedade" (CLAPARÈDE, 1973, p.192).

$\mathrm{Na}$ política curricular examinada, em seus processos de customização, notamos que a ênfase não é atribuída às aptidões dos estudantes para diferentes campos do saber, tal como o sistema claparediano. No Ensino Médio Politécnico, tal como argumentamos até este momento, a centralidade dos processos de escolha está na vontade dos indivíduos em produzir uma escola personalizável, ou mesmo nas possíveis contribuições desse modelo ao campo do desenvolvimento econômico. ${ }^{11}$ A perspectiva de conjugar políticas de escolarização ao desenvolvimento econômico é evidenciada nos objetivos de determinadas ações, tais como "integrar o conjunto de ações que visam a agregar qualidade ao desenvolvimento do Estado" (RIO GRANDE DO SUL, 2011, p.7).

Para agregar qualidade ao desenvolvimento do Estado, sobretudo a partir da emergência de novas configurações capitalistas, a proposta pedagógica examinada apregoa uma concepção de formação escolar para 
o Ensino Médio que vise a uma intelectualização das competências e a uma flexibilidade e capacidade para mudar. ${ }^{12}$ Os excertos abaixo são exemplares nessa direção.

Ou seja, passa a ser necessário o domínio das capacidades de trabalhar intelectualmente e de dominar as categorias do método científico, para acompanhar a dinamicidade da produção em ciência e tecnologia que caracterizam os processos sociais e produtivos contemporâneos, em que novos problemas surgem cotidianamente ao tempo em que conhecimentos e ocupações vão-se tornando obsoletos (RIO GRANDE DO SUL, 2011, p.12).

A capacidade de fazer passa a ser substituída pela intelectualização das competências, que demanda raciocínio formal, domínio das formas de comunicação, flexibilidade para mudar, capacidade de aprender permanentemente e resistência ao estresse (RIO GRANDE DO SUL, 2011, p.13).

Para produzir seu objetivo, a proposta considera como indispensável a superação da lógica disciplinar. "O ponto de partida para essa construção são os processos de trabalho, objetos da formação, de modo a superar a lógica disciplinar e a superposição de conteúdos gerais e específicos, para o que novas formas de seleção e organização do conhecimento são necessárias" (RIO GRANDE DO SUL, 2011, p.15). O Ensino Médio Politécnico, em sua concepção pedagógica, parte da perspectiva de que a formação das competências necessárias para os novos sistemas produtivos somente pode ser realizada através de novas lógicas de seleção e organização dos conhecimentos.

A formação direcionada para a comunicação, para a flexibilidade, para a capacidade de aprendizagem permanente e para a resistência ao estresse é posicionada em um conjunto de estratégias que desenvolvam o protagonismo juvenil. Tal protagonismo vincula-se à premissa de educar os estudantes tanto para a intervenção social, quanto pelas iniciativas vinculadas ao educar pela pesquisa. Em razão dessa concepção, que a proposta examinada, tal como já assinalamos anteriormente, posiciona o currículo como "um conjunto de atividades desafiadoras da capacidade de todos". Acerca das relações sobre o educar pela pesquisa, os fragmentos abaixo produzem outro campo de visibilidades.

Uma das características mais marcantes das novas gerações é a curiosidade inquietante para conhecer e transformar o mundo. Nada mais natural, não 
fossem as relações desiguais que, desde muito cedo, desvelam os caminhos para a inserção social e no mundo do trabalho (RIO GRANDE DO SUL, 2011, p.22).

A pesquisa é o processo que, integrado ao cotidiano da escola, garante a apropriação adequada da realidade, assim como projeta possibilidades de intervenção. Ela alia o caráter social e o protagonismo dos sujeitos pesquisadores (RIO GRANDE DO SUL, 2011, p.22).

Sob essa gramática, o Ensino Médio Politécnico coloca em ação dois sistemas de raciocínio pedagógico: por um lado, a partir da centralidade das opções dos estudantes, mobiliza dispositivos de customização curricular; por outro, dispõe-se a contribuir na formação de jovens protagonistas, empreendedores e pesquisadores. Tais perspectivas ganham em produtividade sob as condições de uma sociedade caracterizada como pósindustrial e de uma configuração flexível do capitalismo, nas quais a formação de sujeitos protagonistas e o desenvolvimento de práticas educativas direcionadas para a formação tecnocientífica tornam-se sentidos fundamentais da escolarização pública. A intenção mobilizada, sob essa grade de inteligibilidade, posiciona-se na premissa de educar sujeitos para intervirem em um mundo competitivo e inovador. A educação permanente, nos moldes descritos pelos grandes arautos do neoliberalismo, apresentase como a estratégia de intervenção privilegiada.

Conforme assinalam Popkewitz, Olsson e Petersson (2009), diferentemente das versões modernas do cosmopolitismo, nas quais, através do uso da razão, o ser humano agia no mundo, visando ao progresso, em nosso tempo, marcado pela sociedade de aprendizagem, configura-se a emergência de um "cosmopolita inacabado". Esse cosmopolita é posicionado, em sua individualidade, como um sujeito em aprendizagem permanente, um agente na resolução de problemas. Segundo os pesquisadores, "trata-se de uma individualidade que projeta a vida como uma contínua solução de problemas, que faz do indivíduo um ser capaz de escolher e de colaborar em comunidades de aprendentes num processo de permanente inovação" (POPKEWITZ; OLSSON; PETERSSON, 2009, p.76). Os processos educativos derivados desse processo, tanto nas reformas curriculares quanto nas políticas de formação docente, tendem a posicionar a inovação como o grande conceito pedagógico do século XXI (POPKEWITZ, 2009). 
De outra perspectiva teórica, o sociólogo Licínio Lima (2012), ao examinar documentos de agências multilaterais, assinala os processos de ajustamento que visam a uma adequação aos sujeitos objetivando a empregabilidade e a competitividade econômica. As formas de escolarização são reduzidas à dimensão econômica; em geral, "retorna-se à ideia do necessário investimento na educação, na pesquisa e na inovação como elementos de regeneração da economia e da sociedade" (LIMA, 2012, p.19). Ao ingressarem na lógica neoliberal do capital humano, os processos educativos assumem uma dupla missão: investir no potencial dos indivíduos para ampliar a competitividade das empresas e dos Estados. Assim, o conhecimento escolar é dimensionado a partir de uma perspectiva focalista, na qual "a ideia de escolha das oportunidades de aprendizagem passou a ser central, fruto de estratégias e racionalidades individuais, típicas de clientes e de consumidores de uma indústria de prestação de serviços" (LIMA, 2012, p.33). Na acepção do sociólogo, as aprendizagens tornamse assunto de ordem individual, regidas pela lógica do "aprender para ganhar" e do "conhecer para competir" (LIMA, 2012, p.41).

Ampliando o escopo da análise, em um texto recente, Beatriz Sarlo elaborou uma crítica cultural sobre os discursos contemporâneos referentes à crise das instituições escolares (SARLO, 2005). Produziu uma densa reflexão sobre as dificuldades da cultura da palavra nas sociedades ocidentais, sobre as dificuldades da administração escolar em garantir qualidade para a educação e dos debates contemporâneos sobre a necessidade de as escolas utilizarem-se das habilidades adquiridas pelos estudantes nas novas formas de comunicação e de entretenimento. Entretanto, para além dessa importante pauta cultural tecida em nosso tempo, Sarlo atribui centralidade aos modos pelos quais a aquisição de uma cultura comum, importante ideal democrático, tem sido "desprezada" pelas novas políticas de escolarização pública.

Sua argumentação parte de um diagnóstico em que, em seu país, "a distribuição desigual das oportunidades educacionais é mais do que injusta: é, simplesmente, criminosa" (SARLO, 2005, p.101). Segundo a pesquisadora, a escola contemporânea tem-se constituído como um espaço de pobreza simbólica: tanto pela ausência do Estado na operacionalização de determinadas políticas, quanto pela incapacidade das escolas em articular "novas sínteses culturais". Os discursos sobre essa instituição estariam envolvidos por abordagens difusas, atravessadas de lugares- 
comuns, expressos (na maioria das vezes) na formulação: "Um ensino tecnicamente moderno deve preparar para o trabalho e ser, também, interessante para os alunos" (SARLO, 2005, p.102). A configuração das políticas de escolarização produzidas em nosso tempo, tal como aquela analisada neste texto, estabelece uma vinculação entre Estado e mercado e confia aos indivíduos a responsabilidade pela sua própria formação.

A argumentação crítica proposta por Sarlo conduz a um aspecto central de nossas políticas de escolarização: o esvaziamento da transmissão cultural. A autora sintetiza essa perspectiva na afirmativa de que "a escola não deve oferecer apenas uma máquina formal, mas também a substância que esta máquina processa" (SARLO, 2005, p.103). Nessa gramática, a escola não pode ser lida apenas como um espaço catalisador de habilidades, nem mesmo um aglutinador das experiências dos estudantes, o que implicaria uma "espécie de autoabastecimento infantil" (SARLO, 2005, p.103). Atualmente, as escolas consideradas mais avançadas "são aquelas que adulam os jovens, e que chegam a tratá-los como clientes" (SARLO, 2005, p.107). Em uma crítica perspicaz, a pesquisadora argentina indica que considerar apenas os interesses dos estudantes e tratar os estudantes como clientes são posturas que delineiam o "viés mercantill" da escola atual. $\mathrm{Na}$ esteira dessa argumentação, indica que as instituições escolares não podem ficar circunscritas somente ao que interessa ao seu público, mas apresentar condições críticas para conduzi-los, pedagogicamente, a um modo de vida democrático.

As análises de Popkewitz (2009), Lima (2012) e Sarlo (2005), de perspectivas teóricas diferentes, apresentam-nos elementos para compreender os sistemas de raciocínio pedagógico que emergem das pautas sociais de nosso tempo. Os sujeitos em aprendizagem permanente, a formação de protagonistas, as comunidades de aprendizagens, a resolução de problemas, a gramática das escolhas individuais e das oportunidades, a mercantilização do conhecimento, o autoabastecimento infantil ou mesmo o enfraquecimento da transmissão cultural, descritos pelos autores, são conceitos observáveis nas seções deste texto, que analisaram a proposta pedagógica do Ensino Médio Politécnico, reforma curricular do Estado do Rio Grande do Sul. O currículo do Ensino Médio, descrito em nossas análises, ainda que se justifique de forma comprometida politicamente com um mundo em transformação, articula-se produtivamente com as novas gramáticas econômicas da sociedade contemporânea. 
Nossas futuras investigações seguirão acompanhando os processos de implementação dessa reforma, aprofundando seus modos de controle e regulação do conhecimento escolar na interface com os fazeres docentes, com a ampliação dos tempos escolares e com as demandas sociais por justiça escolar.

\section{NOTAS}

1 Ainda que o filósofo não se tenha debruçado sobre temas educacionais, ao longo das últimas duas décadas, intensificaram-se os estudos e pesquisas que, valendo-se de suas contribuições teóricas, colocam em questão os temas e problemas educacionais de nosso tempo (SILVA, 2007; VEIGA-NETO, 2008).

2 Sennett (2001) informa-nos, ainda, de que tal estado de risco produz na subjetividade dos trabalhadores uma permanência na ambiguidade e na incerteza; na medida em que, na ausência de uma estrutura burocrática, as redes flexíveis não oferecem campos de planejamento a longo prazo ou mesmo de progressão profissional.

3 Michel Foucault, em seu curso de 1979, no Collège de France, argumenta que o neoliberalismo americano, em suas práticas governamentais, "consome liberdades" (FOUCAULT, 2008b, p.86); por isso, sua intensa preocupação em fabricá-las e organizá-las.

$4 \mathrm{Na}$ introdução da Proposta Pedagógica do Ensino Médio Politécnico, assinala-se a articulação com as novas diretrizes curriculares para a Educação Básica, assim como, em várias partes da proposta, é referido o documento Protótipos Curriculares para o Ensino Médio, produzido pela Unesco.

5 Em um exame minucioso do documento, não encontramos nenhuma citação, direta ou indireta, do pensamento social de Antônio Gramsci, considerado como criador do conceito.

6 Isso pode ser evidenciado na perspectiva de que o pensamento gramsciano sobre a educação atribui centralidade à democratização do acesso aos saberes historicamente produzidos pela humanidade.

7 As Diretrizes Curriculares Nacionais para o Ensino Médio, em seu art. 14 (itens XI e XII), ao delinear as formas de oferta e organização do ensino, assinalam que se faz necessário oferecer aos estudantes "tempos e espaços próprios para estudos e atividades que permitam itinerários opcionais diversificados” (BRASIL, 2012).

8 Essa tendência também pode ser observada em Young (2011).

9 São exemplares dessa tendência os seguintes sites: www.artcorbrasil.com.br/blog/aarte-de-customizar/; pitacodamoda.blogspot.com/2012; customizando.net/customizacao/.

10 Peter Drucker, ao descrever aspectos da vida social no capitalismo contemporâneo, sugere que, "na sociedade do conhecimento, as matérias podem ser menos importantes 
que a capacidade dos estudantes para continuar aprendendo e que a sua motivação para fazê-lo" (DRUCKER, 1993, p.156).

11 Ao analisar as escolas, no contexto neoliberal, Laval (2004) observa uma ênfase em conhecimentos técnicos e saberes úteis. Isso conduziria, em seu entendimento, a uma inversão educativa e a uma redução dos conhecimentos ensinados.

12 Peter Drucker, um dos ícones na divulgação do pensamento neoliberal para as organizações, defende que, no futuro, "todos deverão ser capazes de elevar o rendimento do conhecimento” (DRUCKER, 1993, p.159).

\section{REFERÊNCIAS}

BALL, Stephen; MAINARDES, Jeferson (Orgs.). Políticas educacionais: questões e dilemas. São Paulo: Cortez, 2011.

BALL, Stephen. Performatividades e fabricações na Economia Educacional: rumo a uma sociedade performativa. Educação e Realidade, Porto Alegre, v.35, n.2, p.37-55, 2010. BELL, Daniel. $O$ advento da sociedade pós-industrial: uma tentativa de previsão social. São Paulo: Cultrix, 1977.

BRASIL. Diretrizes Curriculares Nacionais para o Ensino Médio. Brasília: CNE, 2012.

CHARLOT, Bernard. A escola e o trabalho dos alunos. Sisifo: Revista de Educação, Lisboa, n.10, p.89-96, 2009.

CLAPARÈDE, Edouard. A escola sob medida: estudos complementares sobre Claparède e sua doutrina. Rio de Janeiro: Fundo de Cultura, 1973.

DEAN, Mitchell. Governmentality: power and rule in modern society. London: Sage, 1999. DRUCKER, Peter. Sociedade pós-capitalista. São Paulo: Pioneira Thompson Learning, 1993.

DUSSEL, Inés. A transmissão cultural assediada: metamorfoses da cultura comum na escola. Cadernos de Pesquisa, São Paulo, v.39, n.137, p.351-365, maio/ago. 2009.

FABRIS, Elí Teresinha Henn. A escola contemporânea: um espaço de convivência? Anais da $30^{\circ}$ Reunião Anual da ANPED. Rio de Janeiro: ANPED, 2007.

FABRIS, Elí Teresinha Henn; TRAVERSINI, Clarice. Conhecimentos escolares sob outras configurações: efeitos das movimentações disciplinares e de controle. Anais da $34^{\circ}$ Reunião Anual da ANPED. Rio de Janeiro: ANPED, 2011.

FIMYAR, Olena. Governamentalidade como ferramenta conceitual na pesquisa de políticas educacionais. Educação e Realidade, Porto Alegre, v.34, n.2, p.35-56, 2009.

FOUCAULT, Michel. Segurança, território, população. São Paulo: Martins Fontes, 2008 a.

FOUCAULT, Michel. O nascimento da biopolitica. São Paulo: Martins Fontes, 2008b.

FRIEDMAN, Milton. Capitalismo e liberdade. São Paulo: Artenova, 1977.

GADELHA, Sylvio. Biopolítica, governamentalidade e educação: introdução e conexões a partir de Michel Foucault. Belo Horizonte: Autêntica, 2009.

GRINBERG, Silvia. Educación y gubernamentalidad en las sociedades de gerenciamento. Revista Argentina de Sociologia, Buenos Aires, v.4, n.6, p.67-87, 2006.

LAVAL, Christian. La escuela no es una empresa. Barcelona: Paidós, 2004. 
LIBÂNEO, José Carlos. O dualismo perverso na escola pública brasileira: escola do conhecimento para os ricos, escola do acolhimento social para os pobres. Educação e Pesquisa, São Paulo, v.38, n.1, p.13-28, 2012.

LIMA, Licínio. Aprender para ganhar, conhecer para competir. São Paulo: Cortez, 2012.

LOPES, Alice Casimiro; MACEDO, Elizabeth. Teorias do currículo. São Paulo: Cortez, 2011.

LOPES, Maura Corcini. Políticas de inclusão e governamentalidade. Educação e Realidade, Porto Alegre, v.34, n.2, p.153-170, maio/ago. 2009.

MOREIRA, Antônio Flávio Barbosa. Lendo Stella: um mote para pensar o fundamental na escola de ensino fundamental. Revista da FAEEBA - Educação e Contemporaneidade, Salvador, v.19, n.34, p.193-205, 2010.

MOREIRA, Antônio Flávio Barbosa. Por que ter medo dos conteúdos? In: PEREIRA, Maria; MOURA, Arlete (Orgs.). Políticas e práticas curriculares: impasses, tendências e perspectivas. João Pessoa: Ideia, 2005. p.11-42.

MOREIRA, Antônio Flávio Barbosa; CANDAU, Vera. Indagações sobre currículo: currículo, conhecimento e cultura. Brasília: MEC/SEB, 2008.

MULLER, Johan. Revisitando o progressivismo: Ethos, política, Pathos. In: GARCIA, Regina Leite; MOREIRA, Antônio F. B. (Orgs.). Currículo na contemporaneidade: incertezas e desafios. São Paulo: Cortez, 2003. p.293-318.

NARODOWSKI, Mariano. Después de classe: desencantos y desafios de la escuela actual. Buenos Aires: Novedades Educativas, 1999.

NOGUERA, Carlos. La gubernamentalidad en los cursos del profesor Foucault. Educação e Realidade, Porto Alegre, v.34, n.2, p.21-34, 2009.

NÓVOA, Antonio. Professores: imagens do futuro presente. Lisboa: Educa, 2009.

Ó, Jorge Ramos do. O governo de si mesmo: modernidade pedagógica e encenações disciplinares do aluno liceal. Lisboa: Educa, 2003.

PACHECO, José Augusto; PEREIRA, Nancy. Estudos curriculares: das teorias aos projectos de escola. Educação em Revista, Belo Horizonte, v.45, p.197-221, 2007.

PACHECO, José Augusto. Uma perspectiva actual sobre a investigação em Estudos Curriculares. Perspectiva, Florianópolis, v.24, n.1, p.247-272, 2006.

POPKEWITZ, Thomas. El cosmopolitismo y la era de la reforma escolar. Madrid: Morata, 2009.

POPKEWITZ, T.; OLSSON, U.; PETERSSON, K. Sociedade de aprendizagem, cosmopolitismo, saúde pública e prevenção à criminalidade. Educação e Realidade, Porto Alegre, v.34, n.2, p.73-96, maio/ago. 2009.

RIO GRANDE DO SUL. Proposta Pedagógica para o Ensino Médio Politécnico. Porto Alegre: SE, 2011.

ROBERTSON, Susan; DALE, Roger. Pesquisar a educação em uma era globalizante. Educação e Realidade, Porto Alegre, v.36, n.2, p.347-363, 2011.

SARLO, Beatriz. Tempo presente: notas sobre a mudança de uma cultura. Rio de Janeiro: José Olympio, 2005.

SENNETT, Richard. A corrosão do caráter: as consequências pessoais do trabalho no novo capitalismo. 5.ed. Rio de Janeiro: Record, 2001.

SIMONS, Maarten; MASSCHELEIN, Jan. The leaning society and governmentality: an introduction. Educational Philosophy and Theory, Auckland, v.39, n.4, p.417-430, 2006. 
SILVA, Tomaz Tadeu da. Documentos de identidade: uma introdução às teorias do currículo. 2.ed. Belo Horizonte: Autêntica, 2007.

SILVA, Roberto Dias da; FABRIS, Elí Terezinha Henn. O jogo produtivo da educabilidade/governamentalidade na constituição de sujeitos universitários. Revista Brasileira de Educação, Rio de Janeiro, v.15, n.44, p.352-363, 2010.

SILVA, Roberto Rafael Dias da; FABRIS, Elí Terezinha Henn. Os universitários como um público: educação e governamentalidade neoliberal. Educação e Realidade, Porto Alegre, v.37, n.3, p.905-921, set./dez., 2012.

SILVA, Roberto Rafael Dias da. Educação e tecnociência no Brasil contemporâneo: perspectivas investigativas aos estudos curriculares. Ensaio: Pesquisa em Educação em Ciências, Belo Horizonte, v.14, n.2, p.47-60, 2012.

SILVA, Roberto Rafael Dias da. Empreendedorismo e gestão dos talentos na constituição do universitários contemporâneos. Linhas Críticas, Brasília, v.17, p.545-560, 2011.

SOUZA, Rosa Fátima de. História da organização do trabalho escolar e do currículo no século XX. São Paulo: Cortez, 2008.

VEIGA-NETO, Alfredo. Crise da modernidade e inovações curriculares: da disciplina para o controle. In: ENCONTRO NACIONAL DE DIDÁTICA E PRÁTICA DE ENSINO, 14. Porto Alegre. Trajetórias e processos de ensinar e aprender: lugares, memórias e culturas. Porto Alegre: EDIPUCRS, 2008. p.1-18.

UNESCO. Ensino de ciências: o futuro em risco. Edições UNESCO, maio, p.1-5, 2005.

YOUNG, Michael. O futuro da educação em uma sociedade do conhecimento: a defesa radical de um currículo disciplinar. Cadernos de Educação, São Paulo, n.38, p.395-416, 2011. YOUNG, Michael. Para que servem as escolas? Educação e Sociedade, Campinas, v.28, n.101, p.1.287-1.302, 2007.

Recebido em: $17 / 05 / 2013$

Aprovado em: 20/12/2013

Contato:

Universidade Federal da Fronteira Sul

Avenida Dom João Hoffmann, 313

CEP: $99700-000$

Erechim | RS | Brasil 